
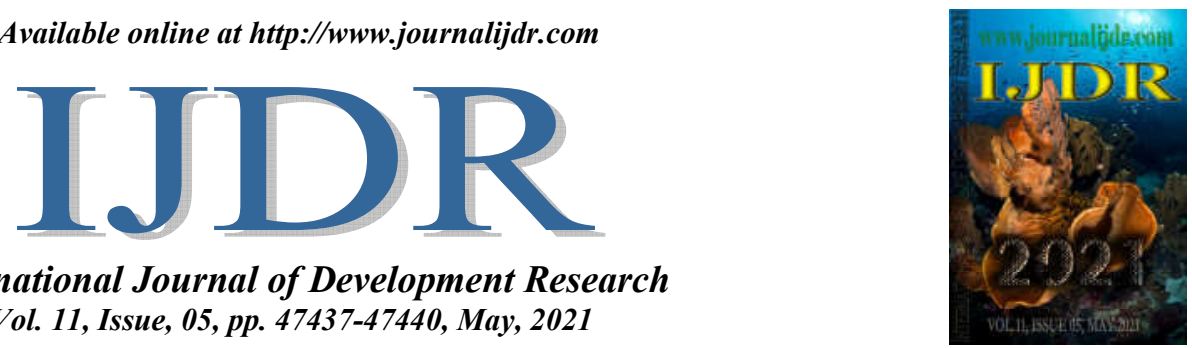

ISSN: 2230-9926

International Journal of Development Research

Vol. 11, Issue, 05, pp. 47437-47440, May, 2021

https://doi.org/10.37118/ijdr.22034.05.2021

\title{
A PSICOMOTRICIDADE COMO INSTRUMENTO DE INCLUSÃO
}

\section{Elaine de Lima Bragança, Especialista em Educação Física Escolar, Professora de Educação Física and Educação Física}

Endereço, Estrada dos Palmares, 105 bl. 10 ap.301, Paciência - Rio de Janeiro - RJ

\section{ARTICLE INFO}

\section{Article History:}

Received $11^{\text {th }}$ February, 2021

Received in revised form

$21^{\text {st }}$ March, 2021

Accepted $18^{\text {th }}$ April, 2021

Published online $30^{\text {th }}$ May, 2021

Key Words:

Criança, Psicomotricidade, Inclusão e

Aprendizagem.

*Corresponding author:

Angélica de Godoy Torres Lima

\begin{abstract}
Muitos têm sido os desafios que os professores da escola regular encontram no trabalho com crianças com deficiências. A psicomotricidade como instrumento de inclusão vai impactarnesse trabalho para explorar o ambiente, desenvolver o tato, o olfato, o esquema corporal, a imagem corporal, a lateralidade, enfim, o desenvolvimento motor, afetivo e social. Para que esse processo de desempenho e crescimento das crianças aconteça, há que se fomentar atividades não só específicas, mas criativas e libertadoras ao pensamento e à imaginação, envolvendo as potencialidades do seu intelectual, físico, social e emocional.
\end{abstract}

Copyright (C) 2021, Elaine de Lima Bragança et al. This is an open access article distributed under the Creative Commons Attribution License, which permits unrestricted use, distribution, and reproduction in any medium, provided the original work is properly cited.

Citation: Elaine de Lima Bragança, Especialista em Educação Física Escolar, Professora de Educação Física and Educação Física. “A Psicomotricidade como instrumento de inclusão”, International Journal of Development Research, 11, (05), 47437-47440.

\section{INTRODUCTION}

A psicomotricidade pode contribuir e muito na aprendizagem das crianças com deficiência. Essa ciência é muito abrangente e tem relações que podem integrar aspessoas, especificamente, as crianças com deficiência, e auxiliar no desenvolvimento como um todo.

O processo do esquema corporal, orientação espaço - temporal, lateralidade, desenvolvimento motor e preescrita são essenciais na aprendizagem e são trabalhadas de forma a aprimorar esses aspectos e conectar essas crianças com o mundo em que vivem.Ao percebermos qualquer problema em um desses, a aprendizagem pode ser prejudicada. Este trabalho tem por objetivo saber como a psicomotricidade pode estimulara aprendizagem das crianças com deficiência. Na educação inclusiva, podemos oferecer igualdade de oportunidades, independentemente de suas diversidades sociais, culturais, intelectuais, sensoriais, de gênero ou mesmo étnicas. Para que a inclusão aconteçaé necessário conhecer cada indivíduo e suas implicações. Ao observar alguns conceitos de psicomotricidade apresentados abaixo, pode-se fomentar um trabalho específico que vai engendrar melhoras significativas no desenvolvimento das crianças com deficiência, através de um processo de abordagens física, afetiva, cognitiva e social:
Psicomotricidade é um termo empregado para uma concepção de movimento organizado e integrado, em função das experiências vividas pelo sujeito cuja ação é resultante de sua individualidade, sua linguagem e sua socialização." (Associação Brasileira de Psicomotricidade)

"Porque a motricidade e posteriormente, a psicomotricidade representam a maturação do Sistema Nervoso Central, é compreensível que os problemas psicomotores, mais do que os motores, sejam evidenciados pelas crianças com dificuldade de aprendizagem". (Fonseca, 1985, p.285)

"A psicomotricidade possui as linhas de atuação educativa, reeducativa, terapêutica, relacional, aquática e ramain". (Associação Brasileira de Psicomotricidade)

\section{METODOLOGIA}

Este trabalho foi realizado através de uma pesquisa de natureza qualitativa, uma revisão da literatura existente em fontes bibliográficas, artigos, livros, revistas, sites e publicações. 
Segundo Turato (2005) é possível realizar uma pesquisa revisando bibliografias e chegar a um entendimento do assunto tratado:

"Não é necessário mensurar ou delimitar, mas tem como objetivo um entendimento mais aprofundado, adentrando a subjetividade dos fenômenos.O que as "coisas" (fenômenos, manifestações, ocorrências, fatos, eventos, vivências, ideias, sentimentos, assuntos) representam, dá molde à vida das pessoas". (Turato,2005)

\section{Psicomotricidade, tipo de deficiências e educação inclusiva}

\section{O Que é a psicomotricidade?}

Pode-se dizer que a psicomotricidade é a ciência que trabalha o desenvolvimento motor das crianças relacionando-o com o seu mundo interno e externo. Ela busca trabalhar, através do corpo e sua interação com o meio, odesenvolvimento não só motor, mas afetivo, cognitivo e social do indivíduo. Atividades sensoriais, motoras, de equilíbrio, de agilidade, de lateralidade, de coordenação motora, jogos, memória e percepção espaço-temporal são "aspectos" trabalhados na psicomotricidade, atuando diretamente nas áreas emocionais, psicológicas, intelectuais e sociais de cada criança. $\mathrm{Na}$ educação escolar, a psicomotricidade precisa ser trabalhada através de um planejamento organizado e interdisciplinar com o objetivo no desenvolvimento integral da criança observando o contexto não só escolar, mas social, familiar, tudo aquilo que se refere à vivência e a realidade na qual a criança está inserida. Abaixo segue dois conceitos muito interessantes da psicomotricidade:

"A Psicomotricidade baseia-se em uma concepção unificada da pessoa, que inclui as interações cognitivas, sensório-motoras e psíquicas na compreensão das capacidades de ser e de expressarse, a partir do movimento, em um contexto psicossocial". (Costa,2002)

Ela se constitui por um conjunto de conhecimentos psicológicos, fisiológicos, antropológicos e relacionais que permitem, utilizando o corpo como mediador, abordar o ato motor humano com o intento de favorecer a integração deste sujeito consigo e com o mundo dos objetos e outros sujeitos." (Costa,2002)

Leis, Dercetos e Declarações sobre Pessoas com Deficiência: Ao pesquisar sobre pessoas com deficiência, percebe-se que há muitas leis, decretos e declarações que buscam contribuir para o direito de ir e vir dessas pessoas. Todas essas leis, decretos e declarações se tornaram necessárias para que as pessoas com deficiência possam ter acesso a qualquer local como locomoção (acesso e plataformas adaptadas), leitura em braile, comunicação em libras e conscientização da limitação de cada indivíduo, mas também respeitar cada um, pois cada qual tem suas aptidões e capacidades de se desenvolver de forma autônoma. As leis, decretos e declarações relacionados à pessoa com deficiência versam sobre direitos, igualdade de oportunidades, de acesso ao sistema regular de ensino, tratando, também, a formação dos docentes que atuam com a educação inclusiva, buscando alcançar independência e participação das pessoas (crianças) com deficiência e que a Educação, como um todo, é um direito de todos e dever do Estado. Segue abaixo algumas leis, decretos e declarações relevantes sobre pessoas com deficiência.

"Considera-se pessoa com deficiência aquela que tem impedimento de longo prazo de natureza física, mental, intelectual ou sensorial, o qual, em interação com uma ou mais barreiras, pode obstruir sua participação plena e efetiva na sociedade em igualdade de condições com as demais pessoas”.(Lei Brasileira de Inclusão, 2015)

"O direito à educação, com base na Convenção sobre os direitos das pessoas com deficiência, que deve ser inclusiva e de qualidade em todos os níveis de ensino; garantir condições de acesso, permanência, participação e aprendizagem, por meio da oferta de serviços e recursos de acessibilidade que eliminem as barreiras". (Lei $\mathrm{n}^{\circ} 13.146$ - Lei brasileira de inclusão da pessoa com deficiência (LBI),2015, cap.IV)

"A educação como um direito de todos, que garante o pleno desenvolvimento da pessoa, o exercício da cidadania e a qualificação para o trabalho. Estabelece a igualdade de condições de acesso e permanência na escola como um princípio. Por fim, garante que é dever do Estado oferecer o atendimento educacional especializado (AEE), preferencialmente na rede regular de ensino". (Constituição Federal,1988, o artigo 205)

"Recomenda a inclusão de conteúdos relativos aos aspectos éticos, políticos e educacionais da normalização e integração da pessoa portadora de necessidades especiais nos currículos de formação de docentes". (Portaria do Ministério da Educação $\left(\right.$ MEC) $\left.n^{\circ} 1.793,1994\right)$

"A educação especial, assegura o atendimento aos educandos com necessidades especiais e estabelece critérios de caracterização das instituições privadas sem fins lucrativos, especializadas e com atuação exclusiva em educação especial para fins de apoio técnico e financeiro pelo poder público". (Lei no 9.394 - Lei de diretrizes e bases da educação nacional (LDB), 1996)

"O nosso compromisso com a Educação para Todos, reconhecendo a necessidade e urgência do providenciar educação para as crianças, jovens e adultos com necessidades educacionais especiais dentro do sistema regular de ensino". (Declaração de Salamanca (Espanha),1994)

Todas essas leis, decretos e declaraçõesbuscam um só objetivo o desenvolvimento integral da criança com deficiência de forma igualitária e adaptada, onde políticas públicas de incentivo, de adaptações de espaços públicos, particulares e escolares, e também, a formação continuada dos professores e profissionais envolvidos utilizando os processos educacionais nos aspectoscognitivo, afetivo e motor, observando sempre a individualidade e o contexto social de cada indivíduoque vão contribuir para alcançar esse objetivo.

Tipos de Deficiência: Não podemos falar da psicomotricidade na educação inclusiva, sem conhecer os tipos de deficiência. É preciso saber que tipo de deficiência aquela criança tem para poder planejar, organizar e selecionar atividades que contribuirão para o desenvolvimento integral da criança.

De acordo com o Censo 2010, quase 46 milhões de brasileiros, cerca de $24 \%$ da população, declarou ter algum grau de dificuldade em pelo menos uma das habilidades investigadas (enxergar, ouvir, caminhar ou subir degraus), ou possuir deficiência mental / intelectual.

"Considerando somente os que possuem grande ou total dificuldade para enxergar, ouvir, caminhar ou subir degraus (ou seja, pessoas com deficiência nessas habilidades), além dos que declararam ter deficiência mental ou intelectual, temos mais de 12,5 milhões de brasileiros com deficiência, o que corresponde a $6,7 \%$ da população". (IBGE,2010)

Pode-se ver que existe na legislação brasileira versando sobre os tipos de deficiência, como no Decreto $n^{\circ}$ 5.296/2004: deficiência física, auditiva, visual, mental (atualmente intelectual, função cognitiva) e múltipla, que é a associação de mais de um tipo de deficiência (BRASIL, 2004).

Encaixam-se nas categorias do Decreto $n^{\circ} 5.296 / 2004$ :

Deficiência física: alteração completa ou parcial de um ou mais segmentos do corpo humano, acarretando o comprometimento da 
função física, apresentando-se sob a forma de paraplegia, paraparesia, monoplegia, monoparesia, tetraplegia, tetraparesia, triplegia, triparesia, hemiplegia, hemiparesia, ostomia, amputação ou ausência de membro, paralisia cerebral, nanismo, membros com deformidade congênita ou adquirida, exceto as deformidades estéticas e as que não produzam dificuldades para o desempenho de funções;

deficiência auditiva: perda bilateral, parcial ou total, de quarenta e um decibéis $(\mathrm{dB})$ ou mais, aferida por audiograma nas frequências de $500 \mathrm{~Hz}, 1.000 \mathrm{~Hz}, 2.000 \mathrm{~Hz}$ e $3.000 \mathrm{~Hz}$;

deficiência visual: cegueira, na qual a acuidade visual é igual ou menor que 0,05 no melhor olho, com a melhor correção óptica; a baixa visão, que significa acuidade visual entre 0,3 e 0,05 no melhor olho, com a melhor correção óptica; os casos nos quais a somatória da medida do campo visual em ambos os olhos for igual ou menor que $60^{\circ}$; ou a ocorrência simultânea de quaisquer das condições anteriores;

deficiência mental: funcionamento intelectual significativamente inferior à média, com manifestação antes dos dezoito anos e limitações associadas a duas ou mais áreas de habilidades adaptativas, tais como:comunicação;cuidado pessoal;habilidades sociais;utilização dos recursos da comunidade;saúde e segurança; habilidades acadêmicas;lazer etrabalho;

deficiência múltipla - associação de duas ou mais deficiências".

Além das deficiências existentes como física, visual, auditiva, mental e múltipla, surgiu uma nova Lei 12.764 de 2012 que considera as pessoas com transtorno do espectro autista uma pessoa com4 deficiência, como citado abaixo:

"Com a Lei 12764/2012, as pessoas com transtorno do espectro autista (TEA) passaram a ser consideradas pessoas com deficiência. Elas apresentam deficiência significativa na comunicação e na interação social. Caracterizam-se por comportamento padrões restritivos e repetitivos de comportamentos, interesses e atividades, manifestados por comportamentos motores ou verbais estereotipados ou por comportamentos sensoriais incomuns; excessiva aderência a rotinas e padrões de comportamento ritualizados; interesses restritos e fixos". (BRASIL, 2012)

Educação Inclusiva: A psicomotricidade na educação inclusiva é de fundamental importância no desenvolvimento das crianças com deficiência, já que as áreas cognitivas, afetivas e/ou motoras podem estar afetadas e causando limitações que a deficiência implica.Trabalhar com atividades específicas que vão atuar diretamente nessas áreas vai contribuire muito no desenvolvimento psicomotor e social das crianças com deficiência.

"A Educação Psicomotora deve ser considerada como uma educação básica para o ensino fundamental. A Educação Psicomotora proporciona atividades escolares, que não podem ser conduzidas se a crianças não tiver alcançado a consciência do seu corpo, lateralizar-se, e se não tiver adquirido habilidades e coordenação de seus gestos e movimentos". (LÊ Boulch, 1987, p.11)

Abaixo pode-se observar o que aLei de Diretrizes Bases da Educação, n 9394/1996 diz sobre educação inclusiva:

"Art. 58. Entende-se por educação especial, para os efeitos desta Lei, a modalidade de educação escolar oferecida preferencialmente na rede regular de ensino, para educandos com deficiência, transtornos globais do desenvolvimento e altas habilidades ou superdotação. (Redação dada pela Lei n 12.796 , de 2013)

$\S 1^{\circ}$ Haverá, quando necessário, serviços de apoio especializado, na escola regular, para atender às peculiaridades da clientela de educação especial.

$\S 2^{\circ} \mathrm{O}$ atendimento educacional será feito em classes, escolas ou serviços especializados, sempre que, em função das condições específicas dos alunos, não for possível a sua integração nas classes comuns de ensino regular.

$\S 3^{\circ} \mathrm{A}$ oferta de educação especial, nos termos do caput deste artigo, tem início na educação infantil e estende-se ao longo da vida, observados o inciso III do art. $4^{\circ}$ e o parágrafo único do art. 60 desta Lei. (Redação dada pela Lei nº 13.632, de 2018)".

O desafio de uma escola inclusiva versa no que diz respeito ao desenvolvimento de uma educação centrada na criança, educar bem, incluindo aquelas que têm limitações. Uma Educação inclusiva é pautada em toda uma organização da Educação começando pelo Estado conectando políticas públicas que vai da adaptação e ruas e calçadas e da escola até a formação do professor para que este esteja preparado para elaborar atividades significativas que vão impactar na integração e no desenvolvimento das crianças com deficiência.

"O currículo deveria ser adaptado às necessidades das crianças, e não vice-versa. Escolas deveriam, portanto, prover oportunidades curriculares que sejam apropriadas a criança com habilidades e interesses diferentes. Crianças com necessidades especiais deveriam receber apoio instrucional adicional no contexto do currículo regular, e não de um currículo diferente". (Declaração de Salamanca,26,27, 1996)

\section{Conclusão}

Conclui-se que a psicomotricidade na educação inclusiva vai muito além de simplesmente oferecer um ambiente adequado e adaptado para crianças com deficiência, vai de encontro ao desenvolvimento motor, afetivo e cognitivo dentro do contexto psicossocial. Através de um planejamento bem pensado e interdisciplinar, áreas como a Pedagogia e a Educação Física podem atuar em conjunto para a aplicação da psicomotricidade na educação inclusiva. É importante ressaltar que o professorprecisa está em constante formação e evolução para conhecer particularidades e implicações das crianças com deficiência, e assim poder trabalhar os conteúdos, fazendo as adaptações necessárias para atender de forma igualitária, sem discriminação, favorecendo a inclusão das mesmas. Pode-se perceber que a psicomotricidade tem muito a contribuir para o desenvolvimento das crianças com deficiência, visto que é uma área muito ampla que atua na educação, na reeducação e, também, como parte terapêutica auxiliando na evolução de cada indivíduo. A psicomotricidade vai trabalhar o esquema e a imagem corporal, proporcionando à criança o conhecimento do seu corpo e suas partes integrantes. Através da lateralidade, os lados direito e esquerdo do corpo da criança são estimulados. A orientação espaço-temporal situa a criança no tempo e espaço. Nesse aspecto, a criança desenvolve o senso de direção, espaço e tempo. A coordenação motora fina e global serão trabalhadas da forma geral para mais especifica, incentivando o desenvolvimento na sua integralidade. Jogos de memória, especialmente, são utilizados para aprimorar a parte intelectual das crianças. Conclui-se que há muitas atividades psicomotoras que podem ser elaboradas e adaptadas para fomentar a educação das crianças com deficiência e que os docentes precisam estar preparados e em constante evolução para realizar esse trabalho e que deve haver uma maior integração entre Estado, Escola e família para promover essa educação inclusiva de forma leve, integrante e significativa para essas crianças.

\section{REFERÊNCIAS}

Brasil. 1996. Declaração de Salamanca e Linha de Ação sobre necessidades Educativas Especiais. Brasília: CORDE.

Brasil. 1996. Ministério da Educação. Lei de Diretrizes e Bases da Educação Nacional. LDB 4.024, de 20 de dezembro de.

Costa, A. C. 2002. Psicopedagogia \& Psicomotricidade: Pontos de interseção nas dificuldades de aprendizagem. 2. ed. Petrópolis: Vozes. 
Fonseca, Vitor DA. 1985. Psicomotricidade. 2. ed. São Paulo: Martins Fontes.

Le Boulch, J. 1982. O desenvolvimento Psicomotor do Nascimento até os seis anos. Porto Alegre: Artes Médicas.

Le Boulch, J. 1987. Educação psicomotora: a psicomotricidade na idade escolar. Porto Alegre: Artes Médicas.

Lei de Diretrizes e Bases - Lei 9.394/96 - LDB: Atualizada - 2019

Turato, Egberto Ribeiro. Métodos qualitativos e quantitativos na área da saúde: definições, diferenças e seus objetos de pesquisa. Rev. Saúde Pública [online]. 2005, vol.39, n.3, pp.507-514. ISSN 1518-8787. http://dx.doi.org/10.1590/S003489102005000300025, acesso em 25/03/2021

Asp, Associação Brasileira de Psicomotricidade. O que é Psicomotricidade. Disponível em: https://psicomotricidade. com.br/sobre/o-que-e-psicomotricidade, acesso em 19/04/2021
Decreto 5296 disponível em: http://www.planalto. gov.br/ccivil_03/_ato2004-2006/2004/decreto/d5296.htm, acesso em $20 / 04 / 2021$

IBGE 2010 disponível em:https://educa.ibge.gov.br/jovens/conhecao-brasil/populacao/20551-pessoas-com-deficiencia.html, acesso em 20/04/2021

Legislação federal brasileira e a educação de alunos com deficiência disponível em: https://diversa.org.br/artigos/a-legislacao-federalbrasileira-e-a-educacao-de-alunos-com-deficiencia/, acesso em $12 / 02 / 2020$

Portaria 1793 disponível em: http://portal.mec.gov.br/arquivos/ pdf/portaria1793.pdf, acesso em 20/04/2021 